\title{
Hoogmoed as motief in die profetiese uitsprake teen nie-Israelitiese volke
}

\author{
FJ Boshoff
}

\section{Abstract \\ Pride as motif in the prophecies against foreign nations}

Pride is a common motif in the prophecies against foreign nations. The concept of pride in these prophecies must be understood in a theological context, i e that everything has its place and function within the world order. Pride represents a short-circuit within this world order. It is God who acts against pride, every time. Significantly, pride as a motif appears especially in times of exile.

\section{VOORKOMS}

Wat die voorkoms betref, kan gesê word dat hoogmoed algemeen voorkom in die profetiese uitsprake teen nie-Israelitiese volke. Jesaja, Jeremia, Esegiël, Sefanja en Sagaria maak almal van hoogmoed as motief gebruik wanneer hulle hul uitsprake teen nie-Israelitiese volke maak.

Dit is egter opvallend dat Amos nie in sy reeks uitsprake teen nieIsraelitiese volke hoogmoed ter sprake bring nie. Amos noem wel baie ander redes waarom die volke gestraf word, maar nie hoogmoed nie.

\section{VORM}

2.1 Ten opsigte van die letterkundige vorm waarin hoogmoed in hierdie uitsprake voorkom, word van ten minste vyf verskillende woordstamme gebruik gemaak: $g^{3} h, g b \underline{h}$, rwm, zyd en $g d l$.

Die betekenis van 'hoog wees' word deur hierdie woorde gedeel (Wharton 1962: 876). Die woordstam $g^{3} h$ is die oorheersende een in die uitsprake teen nie-Israelitiese volke.

2.2 Die profete is skerp in hulle afwysing van hoogmoed by die nieIsraeliteise volke. Terme sóos šbt (Jer 13: 11), špl (Jer 13: 11), yrd (Jes 14: 11; Jer 49: 16), krt (Eseg 29: 8, Sag 9: 4) word gebruik om die uiteinde van die hoogmoed te beskryf. Dit is opvallend dat waar van hoogmoed sprake is, die profete as ' $t$ ware haastig is om die 
gevolge van hoogmoed ook te beskryf; soms nog in dieselfde vers. (Vgl Jes 13: 11; 14: 11, Jer 49: 16; 50: 29-32, Eseg 29: 8-9, Sag 9: 4.)

Jes 16: 6 en Jer 48: 29 is die uitsonderings op hierdie reël.

2.3 Die letterkundige vorm van die uitsprake teen nie-Israelitiese volke toon verder dat waar daar van hoogmoed sprake is, dit in die meeste gevalle God self is wat aan die woord is.

2.3.1 Baie van die uitsprake oor hoogmoed word in die direkte rede geformuleer met God in die eerste persoon: $w^{\text {eh hišbatti }}$

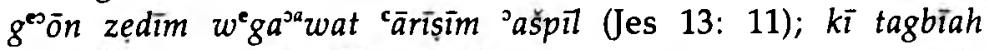
kannešer qinnekā miššām 'orid'k $k \bar{a} n^{\text {es } u m ~ y h w h ~(J e r ~ 49: ~ 16) ; ~}$

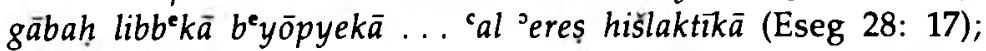

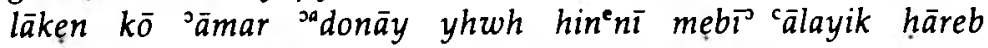
$w^{e}$ hikrattī mimmẹk 'ādām $\bar{u} b^{e} h e m a \bar{a}$ (Eseg 29: 8); wattagdīu 'ālay beikem (Eseg 35: 13); w'hikrattī geōn pelištìm (Sag 9: 6).

2.3.2 Naas hierdie uitsprake waar God in die eerste persoon voorkom, verskyn God op ander plekke egter ook in die derde

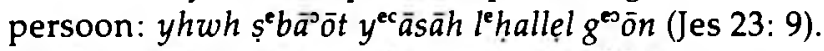

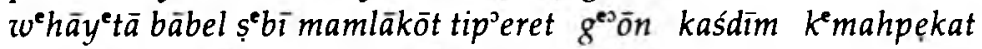
गJōhìm 'et sedōm wes et ${ }^{c a}$ mōrā (Jes 13: 19).

2.3.3 Behalwe die gebruik van die eerste persoon en die derde persoon, word in hierdie profetiese uitsprake van nog 'n formulering gebruik gemaak naamlik die lydende vorm. Jesaja 14: 11 is 'n voorbeeld hiervan: hürad s'es ól $g^{e s} \bar{n}$ ek $\bar{a}$. God wat gewoonlik die subjek van die handelinge teen hoogmoed is, ontbreek hier. Dit word ook nie met ' $n$ ander subjek vervang nie.

2.3.4 Hoogmoed word besonder sterk beklemtoon in Jesaja 16: 6 en Jeremia 48: 29. Sonder om hier in te gaan op die vraag na oorsprong en eenheid van die dele kan wel gesê word dat ons hier ook met ' $n$ unieke hantering van hoogmoed te doen het. Hier word nie direk gesê teen wie die hoogmoed van Moab gemik was nie. Verder ontbreek die subjek wat op die hoogmoed moet reageer. Waarskynlik lê ten grondslag van dié uitsprake die opvatting dat waar onheil is, daar ook skuld moet wees (Wildberger 1978: 625).

2.3.5 Omdat God in die oorgrote meerderheid uitsprake oor hoogmoed die subjek is wat optree teen hoogmoed, kan die afleiding reeds gemaak word dat hoogmoed 'n oortreding teen God is. In Jeremia 50: 29 word reguit gesê dat Babel se hoogmoed teen God gemik is: $k \bar{l}{ }^{`} e l$ yhwh zāda . 
In Sejanja 2: 10 vind ons dat die hoogmoed van Moab nie teen God nie, maar teen die volk gerig is. wayyagdilü ' $a l{ }^{c} a m$ yhwh $s^{e} b \vec{a} \bar{o} t$. Die hoogmoed word hier gespesifiseer as 'n meerderwaardige houding teenoor die volk van God.

Alhoewel die hoogmoed hier teen die volk gemik is, is dit tog indirek hoogmoed teen God self, want God is ook in hierdie geval die Een wat optree teen hoogmoed (Sef 2: 9).

In die profetiese uitsprake teen nie-Israelitiese volke word hoogmoed dus beskou as sonde van die nie-Israelitiese volke teen die God van Israel.

\section{INHOUD}

Ten einde vas te stel wat die inhoud en omvang van die hoogmoed in die profetiese uitsprake teen nie-Israelitiese volke is, is dit nodig dat dié uitsprake van nader bekyk moet word.

\subsection{Jesaja 10: 5-15}

Hierdie is ' $n$ uitspraak teen Assirië. Daar word algemeen aanvaar dat met die uitsondering van 10: 10-12 ons hier outentieke woorde van Jesaja het (Wildberger 1972: 393). Assirië het in die tweede helfte van die agtste eeu opnuut 'n groot wêreldmag geword. Volgens Jesaja word Assirië die instrument waarmee God sy volk gaan straf. Assirië is die draer van God se toorn en grimmigheid (vgl Jes 10: 5). Assirië ontvang 'n buitengewoon wye opdrag: ${ }^{x}$ şawwennū lišlol šâlāl welāboz baz (Jes 10: 6). Volgens Jesaja 10: 7 het Assirië egter sy opdrag oorskry omdat hy nie die grense van sy opdrag eerbiedig nie, maar sy volmag misbruik om sy vyand te vernietig. Die opdrag aan Assirië naamlik straf vir die volk van God, ontaard in 'n vernietigingsorgie (Wildberger 1972: 396).

Die inhoud van Assirië se hoogmoed word geillustreer deur die gedagtes van die koning (vgl Jes 10: 8 en 13). Die sukses wat deur die koning en sy Assiriërs behaal word, gee maklik aanleiding tot selfroem. Die selfroem en eiewaan gaan weer maklik oor tot veragting van die God van Israel.

Hoogmoed is hier dus die oorskryding van die opdrag. Dit is selfroem na sukses. Die valse gevoel van sekuriteit ná rykdom verwerf is en verstandig beplan is, dra by tot die hoogmoed van die Assiriërs.

\subsection{Jesaja 13: 11-12}

Albei hierdie verse is geformuleer as 'n direkte Jahwe-woord. In 13: 11a word $r \bar{a}^{\mathrm{x}} \bar{a}$ en ' $\bar{a} w \bar{w} \bar{n}$ gebruik om die rede vir die straf aan te dui. $11 \mathrm{~b}$ 


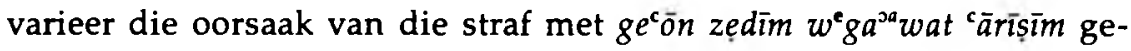
bruik word.

Volgens Jesaja sal alle trotsheid $\left(g^{c} h\right)$ en hoogmoed $(g b h)$ van mense op die dag van God verneder en vernietig word (Wildberger 1972: 517).

\subsection{Jesaja 13: 19-22}

In hierdie deel word die ondergang van Babel konkreet beskryf. Babel word beskryf as $s^{e} b \bar{\imath}$ mamlākōt en tip eret $g^{e} \bar{o} n$ kaśdìm. Die skrywer kondig aan dat dieselfde lot die hoogmoedige Babel gaan tref as wat Sodom en Gomorra getref het.

Saam met Wildberger kan hier aanvaar word dat Babel nie tot niet gaan as gevolg van wraak oor die onreg wat teen Israel gepleeg is nie, maar sy ondergang het hy te wyte aan sy hoogmoed wat gespesifiseer word as $r \bar{a}^{c} \bar{a}$ en ' $\vec{a} w \bar{o} n$ (Jes 13: 11).

\subsection{Jesaja 14: 9-13}

Hier het ons te doen met ' $n$ lied wat ook buite-Israelitiese mitiese stof verwerk. Binne hierdie Gattung van satiriese lyksliedere word waarskynlik ' $n$ tradisie verwerk wat in Israel bestaan het en waarvolgens oor hoogmoed en vernedering van vreemde heersers gespreek is (Wildberger 1972: 543). Wildberger meen verder dat die godsdienstige waarde van hierdie lykslied waarskynlik daarin lê dat dit geregtigheid aankondig wat nou by die Wysheid aansluit.

Jesaja 14: 9-11 bevestig dat Babel se heerlikheid en al die dinge wat hom so trots en hoogmoedig maak, saam met hom in die doderyk gegooi sal word.

\subsection{Jesaja 16: 6-12}

Presies waarin die hoogmoed bestaan het, word nie uitdruklik gesê nie. Tog ken die digter die Moabiete as hoogmoedig (Oberholzer 1970). Hierdie vers gee moontlik die antwoord op die vraag na die oorsaak van die onheil wat Moab moes ervaar. Dit was as gevolg van Moab se hoogmoed. Jeremia 48 toon ooreenkomste met die uitspraak teen Moab in Jesaja 15 en 16. Die verskille is opvallend. Jesaja se uitspraak teen Moab is meer bepaald terwyl Jeremia se uitspraak meer algemeen is. Die afleiding kan daarom gemaak word dat Jesaja ' $n$ stuk gebeure in gedagte het as hy Moab hoogmoedig noem, terwyl Jeremia die hoogmoed aanbied as rede vir die komende oordeel (Wildberger 1972: 605). Jesaja 16: 6 laat die indruk dat hoogmoed, $g \vec{a} \bar{o} n$, tuishoort in die 
staande inventaris van verwyte en beskuldigings teen die nie-Israelitiese volke (Wildberger 1972: 863).

\subsection{Jesaja 23: 9}

Dieselfde verwyt van $g \vec{a} \bar{o} n$ word ook teen die Fenisiërs gerig. Volgens die digter moet die val van die hoogmoedige Tirus nie beskou word as maar net 'n gebeurtenis op die terrein van die wêreldpolitiek nie. Die val en ondergang van Tirus is deur God so beplan: yhwh ș $s^{e} \bar{a} \bar{o} t y^{e c} a \bar{s} a \bar{h} h$. Die besluit van God is nie 'n onbegryplike raaisel nie. Alle hoogmoed word beëindig.

Die hoogmoed van Tirus word in 23: 8 beskryf as sōh ${ }^{2} r \bar{h} h \bar{a}$ is śārim en $k_{i n}{ }^{e c} \bar{a} n e \bar{h} \bar{a}$ nikbaddẹ 'āreș. Prag en praal is die manifestasie van die hoogmoed in Tirus. Volgens Wildberger is die aankondiging van oordeel weens hoogmoed een van die stereotipe motiewe in die profetiese uitsprake teen vreemde volke.

\subsection{Jeremia 48: 29-35}

Soos reeds vroeër aangetoon, loop hierdie deel min of meer parallel met Jesaja 16: 6-12, wat egter nie 'n rede is om die twee dele met mekaar gelyk te stel nie (Van Selms 1974: 31). Omdat nie uitdruklik gesê word waarin die hoogmoed van Moab bestaan het nie, moet ons dus soek na 'n ander rede waarom juis die hoogmoed van Moab so besonder sterk beklemtoon word (Daar word naamlik vyf verskillende woorde gebruik om Moab se hoogmoed mee te beskryf). Die verklaring van Van Selms lyk aanneemlik. Hy meen die bedoeling is dat Juda nie in sy nood weens die Babiloniese verdrukking by Moab moes gaan hulp soek nie.

\subsection{Jeremia 49: 1-6}

Ammon was ook een van die volke wat, nes Moab, 'n anti-Babiloniese koalisie aan Juda voorgestel het. Ook hier lyk dit asof die hoofbedoeling van die uitspraak is om Juda te ontmoedig om in 'n koalisie teen Babel betrokke te raak (Van Selms 1974: 41). Die vertroue wat Ammon in sy eie kragte gestel het (Jer 49: 4), word veroordeel. Hoewel hoogmoed hier nie uitdruklik genoem word nie, is vertroue op eie kragte een van die sterk elemente van hoogmoed.

\subsection{Jeremia 49: 7-22}

Hierdie uitspraak oor Edom is soortgelyk aan die een oor Moab. Volgens 49: 16 is dit God self wat teen Edom uit sy hoë skuilplek aftrek. 


\subsection{Jeremia 50: 29-32}

In hierdie uitspraak teen Babel gaan dit oor vergelding volgens werke. In die besonder word hoogmoed genoem as 'n werk wat vergeld moet word (Van Selms 1974: 60). Hier word die hoogmoed van Babel egter ook nie nader gepresiseer nie.

\subsection{Esegiël 28: 2-10}

In hierdie uitspraak word die koning van Tirus aangespreek juis weens sy hoogmoed. Groot wysheid (28: 3) en rykdom (28: 4) is dikwels die redes waarom 'n mens hoogmoedig word. In Tirus se geval het die aardse voorspoed, hulle veilige woonplek, suksesvolle politiek en sukses op die gebied van die handel hulle verlei om die grens van selfroem te oorskry (Eichrodt 1966: 267). Volgens 28: 6 kom die selfverheffing en hoogmoed te staan voor die oordeel van God.

\subsection{Esegiël 28: 17}

Hier word nog een van die oorsake van Tirus se hoogmoed gespesifiseer, naamlik prag: gāabah libb $k \bar{a} b^{\mathbf{e}}$ yāpyek $\bar{a}$.

\subsection{Sagaria 9: 5-8}

Elliger meen dat die hoogmoed van die Fillistyne hier tot uiting kom in die feit dat hulle nie aandag gee aan die Joodse offergebruike nie (Elliger 1967: 146). Hiervan word egter nie in ons gedeelte gepraat nie. Dit bly steeds God wat die hoogmoed beëindig.

\subsection{Sagaria 10: $1-12$}

Dit gaan in hierdie uitspraak primêr oor heil aan Israel. Om die heil aan Israel te gee, sal al die magte wat in die pad staan, moet wyk en ten

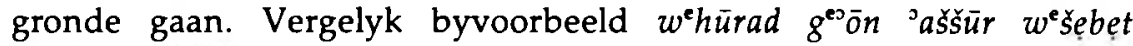
mișrayīm yāsūr (Sag 10: 11).

\subsection{Sefanja 2: 4-15}

In hierdie uitspraak word die hoogmoed van Moab aangedui as wayyagdilū 'al 'am yhwh șebảōt (2: 10). Van der Woude aanvaar hier dat die uitspraak wyer tref as net Ammon en Moab. Dit is dieselfde lot wat alle volke gaan tref wat as gevolg van hulle hoogmoed die heerskappy van God misken (Van der Woude 1978: 120).

Teologies beoordeel, kan op voetspoor van Wildberger gesê word dat elke ding sy plek en funksie het binne die wêreldorde. Geen werktuig 
kan hom beroem teen die een wat hom gebruik het nie. Dit geld ook die mens. Selfs die koning van 'n groot wêreldmag is gebonde aan orde - 'n orde wat hy nie ingestel het of kan ophef nie. Elke mens moet binne die grense van sy sending en opdrag bly. Hoogmoed verteenwoordig 'n kortsluiting binne hierdie wêreldorde. Wie dus só teen die wêreldorde stamp, kry met God te doen. Daarom is dit telkens God wat optree teen die hoogmoed, ook die hoogmoed van die nie-Israelitiese volke.

\section{HOOGMOED DIE REDE VIR ONDERGANG}

Uit die uitsprake kan tot die gevolgtrekking geraak word dat hoogmoed een van die belangrikste redes is vir ondergang, veral by die nieIsraelitiese volke.

In Jesaja 10: 10 word afgode genoem as rede vir die ondergang van Assirië. Amos gee ook 'n hele reeks redes aan waarom vreemde volke ondergegaan het (vgl Amos 1 en 2). Hoewel hoogmoed dus nie die enigste rede is nie, is dit een van die belangrike redes waarom nieIsraelitiese volke ondergegaan het.

\section{DATERING}

Die datering van die uitsprake teen nie-Israelitiese volke met hoogmoed as motief bring ' $n$ interessante resultaat na vore.

\subsection{Jesaja 10: 5-15}

Volgens Wildberger is hierdie stuk, met die uitsondering van 10: 10-12, outentieke Jesajawoorde (Wildberger 1978: 401). Die gedeelte word dus gedateer in die tweede helfte van die agtste eeu toe die Assiriese bedreiging 'n werklikheid was.

\subsection{Jesaja 23: 1-18}

Daar word algemeen aanvaar dat hierdie uitspraak nie van Jesaja kom nie. Die uitspraak dateer egter uit 'n tyd toe Tirus nog 'n belangrike handelsentrum was. Nadat hy ook taal en gedagtes beoordeel het, dateer Wildberger hierdie uitspraak in die laat-Assiriese periode (Wildberger 1978: 865).

\subsection{Sefanja 2: 4-15}

Die agtergrond van hierdie uitspraak is die gebeure rondom die val 
van Jerusalem in $586 \mathrm{vC}$. Dit is moontlik dat die invalle van Moab en Ammon saam met die Galdeërs en Arameërs in omstreeks 600, 'n invloed gehad het op hierdie uitspraak (Van der Woude 1978: 119). Hoewel Sefanja 2: 10-11 dalk van 'n latere redaktor kan kom, stem dié deel baie ooreen met die voorafgaande ten opsigte van woordgebruik. Die uitspraak pas dus in aan die begin van die Babiloniese ballingskap.

\subsection{Jesaja 16: 6 en Jeremia 48: 29}

Beide hierdie uitsprake gaan terug op ou spreuke (Van Selms 1974: 26). Oberholzer kom tot die gevolgtrekking dat, wat Jesaja 16: 6 betref, die herkoms en ontstaantyd duister bly. Van Selms dateer Jeremia 48: 29 in 594. Moab en ander state het toe voorgestel dat Juda met hulle moes saamgaan in 'n koalisie teen Babilonië. As 'n waarskuwing het Jeremia dit nodig gevind om hierdie ou uitsprake teen Moab weer te berde te bring. Op grond van Van Selms se gevolgtrekking lyk dit of Jesaja 16: 6 ook in die vroeë stadiums van die Babiloniese ballingskap tuishoort.

\subsection{Jeremia 49: 1-22 en 50: 29-32}

Van Selms dateer die uitsprake teen Ammon (49: 4) en Edom (49: 16) ook in $594 \mathrm{vC}$. Ammon en Edom was deel van die volke wat Juda by 'n anti-Babiloniese koalisie wou betrek. Deur middel van die uitsprake waarsku Jeremia dat die volk nie op ander volke moet staatmaak nie. Daar is niks wat daarop dui dat die versameling Jeremia 50: 1-51: 64 nie ook in 594 vC gedateer kan word nie (Van Selms 1974: 74).

\subsection{Sagaria 9: 1-6 en 10: 3-12}

Hierdie uitsprake kom voor in Deutero-Sagaria. Elliger dateer die uitsprake in $332 \mathrm{vC}$. Volgens die inhoud is dié dele 'n belofte aan Juda. As deel van die belofte van heil aan Juda word belowe dat die hoogmoed van die Filistyne uitgeroei sal word.

Kuhl toon aan dat alhoewel die stof in Deutero-Sagaria eskatologies is, hierdie uitsprake ou vreemdevolk-profesieë is wat hier verwerk is (1956: 148). Hoewel die uitsprake dus in 'n jonger boek voorkom, is dit uitsprake wat waarskynlik ook in die ballingskaptyd ontstaan het.

\subsection{Esegiël 28 en $\mathbf{2 3}$}

Esegiël het die ballingskap self beleef en sy uitsprake word dus ook as ballingskapuitsprake beskou. 
Die gevolgtrekking Kan' nou gemaak word dat die dreigende ballingskap deur die Asširieërs, maar veral dié deur die Babiloniërs, 'n stimulus was vir uitsprake oor hoogmoed (vgl Jer 48 en Sef 2: 4-15). Nie net die dreigende, komende ballingskap nie, maar ook die ballingskap as voldonge gebeurtenis, gee steeds aanleiding tot die profetiese hoogmoeduitsprake (vgl Jes 13). Die profete se uitsprake oor hoogmoed by die nie-Israelitiese volke ontstaan dus in die ballingskaptyd.

\section{SAMEVATTING}

Hoogmoed is ' $n$ motief wat telkens voorkom wanneer die profete hulle uitsprake teen die nie-Israelitiese volke maak. Hoogmoed van die nieIsraelitiese volke is deurgaans sonde teen God. In tye van ballingskap tree hoogmoed veral sterk na vore as motief in die profetiese uitsprake teen nie-Israelitiese volke.

\section{Literatuurverwysings}

EICHRODT, W 1966. Der Prophet Hezekiel. Göttingen: Vandenhoeck \& Ruprecht. (ATD.) ELLIGER, K 1967. Das Buch der zwölf Kleinen Propheten, 1I. Göttingen: Vandenhoeck \& Ruprecht. (ATD.)

KUHL, C 1956. Israels Propheten. Bern: Francke.

OBERHOLZER, JP 1970. Jesaja $15 \& 16$. Klasaantekeninge, Universiteit van Pretoria.

VAN DER WOUDE, AS 1978. Habakuk, Zefanja. Nijkerk: Callenbach. (De Prediking van het Oude Testament.)

VAN SELMS, A 1974. Jeremia, Deel III en Klaagliederen. Nijkerk: Callenbach. (De Prediking van het Oude Testament.)

WHARTON, JA 1962. sv Pride. IDB, Vol 3.

WILDBERGER, H 1972. Jesaja, 1. Teil, Bd 1-12. Neukirchen: Neukirchener Verlag.

WILDBERGER, H 1978. Jesaja, 2. Teil, Bd 13-27. Neukirchen: Neukirchener Verlag (BK AT.) 